\title{
Modeling and Simulation Multi Motors Web Winding System
}

\author{
Hachemi Glaoui, Abdeldjebar Hazzab, Bousmaha Bouchiba, Ismaïl Khalil Bousserhane \\ Laboratory of command, Analysis and Optimization of the Electro-Energizing Systems, Faculty of Sciences and \\ technology, Béchar University B.P. 417 Béchar, 08000, Algeria
}

\begin{abstract}
Web winding systems allow the operations of unwinding and rewinding of various products including plastic films, sheets of paper, sheets, and fabrics. These operations are necessary for the development and the treatment of these products. Web winding systems generally consist of the same machine elements in spite of the diversity of the transported products. Due to the wide rang variation of the radius and inertia of the rollers the system dynamic change considerably during the winding/ unwinding process. Decentralized PI controller for web tension control and linear speed control are presented in this paper. The PI control method can be applied easily and is widely known, it has an important place in control applications. Simulation results show the effectiveness of the proposed linear speed and tension controller for web winding multi motors systems.
\end{abstract}

Keywords- Multi motors web winding system; PI controller; tension control; linear speed control

\section{INTRODUCTION}

Many types of materials are manufactured or processed in the form of a sheet or a web (textile, paper, metal, etc.) which then couples the processing rolls and the associated motor drives. The drives are required to work in synchronism to ensure quality processing and rewinding of the product. Tension is a very important web manufacturing and process setting. If severe tension variations occur, rupture of the materiel during processing or degradation of product quality can occur, resulting into significant economic losses due to material loss and reduced production rate. Therefore, in order to minimize the potential for loss, the need arises to adequately control the tension within a predefined range in a moving web processing section.

Henceforth, due to their importance in industry, tension control problems have drawn the attention of many researchers. One problem is the establishment of a proper mathematical model. In [1], a mathematical model of a web span is developed, but this model does not predict the tension transfer.

This problem was addressed in [2] and [3], with the assumption that the strain in the web is very small. However, the form of the nonlinear and coupling terms in the model are not always convenient for controller design so that other model structures, with comparable precision, are desirable. Several control strategies have been suggested to maintain quality and reduce sensitivity to external disturbances, including centralized multivariable control schemes for steel mill applications [4][5] and an Hळo control strategy to decouple web velocity and tension [3][6]. Also, for tension regulation in a web transport system, [7] proposed a control method based on a unique active disturbance rejection control (ADRC) strategy, which actively compensates for dynamic changes in the system and unpredictable external disturbances. In [8] and [9], PortControlled Hamiltonian with Dissipation (PCHD) modeling is considered to develop stabilization strategies with a physical interpretation and motivation of the control action, interpreted as the realization of virtual dampers added to the system, which resulted into a type of dual action controller with velocity feedback and velocity error feedback terms. Some limited improvements were obtained in disturbance rejection properties and robustness with respect to some parameter variations. The conventional PI control dominates industry, it is simple and easy to implement [15]. Tuning of PI controllers is intuitive and is well accepted by practitioners. PIs can at most achieve a compromise in performance in terms of system response speed and stability, and this approach becomes insufficient at the increasingly high web velocities demanded by the industry and with thin or fragile materials. Nonlinearities that appear at high velocities, disturbance rejection properties and robustness to some parameter variations must be accounted for by the controller. A decentralized nonlinear PI controller is proposed to respond to this demand. The model of the winding system and in particular the model of the mechanical coupling are developed and presented in Section 2. Section 3 shows the controllers design for winding system. Section 4 shows the Simulation results using Matlab Simulink. Finally, the conclusion is drawn in Section 5.

\section{SyStem ModeL}

In this system, the motor M1 carries out unreeling and M3 is used to carry out winding, the motor M2 drives two rollers via gears "to grip" the band (Fig.1). The stage of pinching off can make it possible to isolate two zones and to create a buffer zone $[8,9]$. The objective of these systems is to maintain the linear speed constant and to control the tension in the band.

The used motors are five phase induction motors type which each one is supplied by an inverter voltage controlled with Pulse Modulation Width (PWM) techniques. A model based on circuit equivalent equations is generally sufficient in order to make control synthesis. The electrical dynamic model of five-phase $\mathrm{Y}$-connected induction motor can be expressed in the d-q synchronously rotating frame as [13]: 


$$
\left\{\begin{array}{l}
\frac{d i_{d s}}{d t}=\frac{1}{\sigma \cdot L_{s}} \cdot\left(-\left(R_{s}+\left(\frac{L_{m}}{L_{r}}\right)^{2} \cdot R_{r}\right) \cdot i_{d s}+\sigma \cdot L_{s} \cdot \omega_{e} \cdot i_{q s}+\frac{L_{m} \cdot R_{r}}{L_{r}^{2}} \cdot \phi_{d r}+\frac{L_{m}}{L_{r}} \cdot \phi_{q r} \cdot \omega_{r}+V_{d s}\right) \\
\frac{d i_{q s}}{d t}=\frac{1}{\sigma \cdot L_{s}} \cdot\left(-\sigma \cdot L_{s} \cdot \omega_{e} \cdot i_{d s}-\left(R_{s}+\left(\frac{L_{m}}{L_{r}}\right)^{2} \cdot R_{r}\right) \cdot i_{q s}-\frac{L_{m}}{L_{r}} \cdot \phi_{d r} \cdot \omega_{r}+\frac{L_{m} \cdot R_{r}}{L_{r}^{2}} \cdot \phi_{q r}+V_{q s}\right) \\
\frac{d \phi_{d r}}{d t}=\frac{L_{m} \cdot R_{r}}{L_{r}} \cdot i_{d s}-\frac{R_{r}}{L_{r}} \cdot \phi_{d r}+\left(\omega_{e}-\omega_{r}\right) \cdot \phi_{d r} \\
\frac{d \phi_{q r}}{d t}=\frac{L_{m} \cdot R_{r}}{L_{r}} \cdot i_{q s}-\left(\omega_{e}-\omega_{r}\right) \cdot \phi_{d r}-\frac{R_{r}}{L_{r}} \cdot \phi_{q r} \\
\frac{d \omega_{r}}{d t}=\frac{P^{2} \cdot L_{m}}{L_{r} \cdot J} \cdot\left(i_{q s} \cdot \phi_{d r}-i_{d s} \cdot \phi_{q r}\right)-\frac{f_{c}}{J} \cdot \omega_{r}-\frac{P}{J} \cdot T_{l}
\end{array}\right.
$$

Where $\sigma$ is the coefficient of dispersion and is given by:

$$
\sigma=1-\frac{L_{m}^{2}}{L_{s} L_{r}}
$$

The tension model in web transport systems is based on Hooke's law, Coulomb's law, [8, 9] mass conservation law and the laws of motion for each rotating roll.

\section{A. Hooke's law}

The tension $\mathrm{T}$ of an elastic web is function of the web strain $\varepsilon$

$$
T=E S \varepsilon=E S \frac{L-L_{0}}{L_{0}}
$$

Where $\mathrm{E}$ is the Young modulus, $\mathrm{S}$ is the web section, $\mathrm{L}$ is the web length under stress and LO is the nominal web length (when no stress is applied).

\section{B. Coulomb's law}

The study of a web tension on a roll can be considered as a problem of friction between solids, see [8] and [9]. On

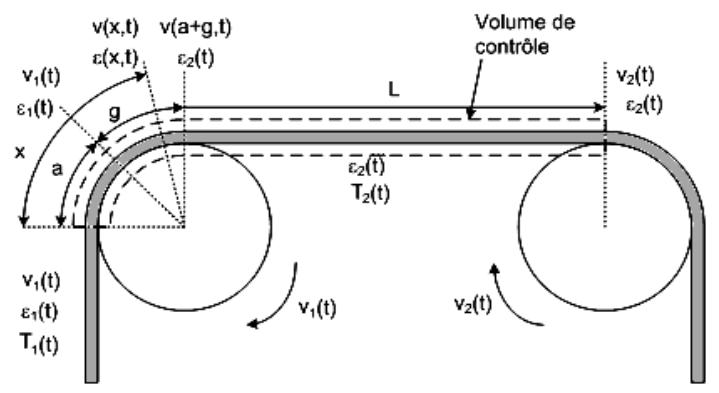

Fig. 1. Web Tension On The Roll

The roll, the web tension is constant on a sticking zone of arc length a and varies on a sliding zone of arc length $\mathrm{g}$ (cf. Fig. 1, where $\mathrm{Vk}(\mathrm{t})$ is the linear velocity of the roll $\mathrm{k})$. The web tension between the first contact point of a roll and the first contact point of the following roll is given by:

$$
\begin{aligned}
& \varepsilon(x, t)=\varepsilon_{1}(t) \\
& \varepsilon(x, t)=\varepsilon_{1}(t) e^{\mu(x-a)} \\
& \varepsilon(x, t)=\varepsilon_{2}(t)
\end{aligned}
$$$$
\text { if } x \leq a
$$$$
\text { if } a \leq x \leq a+g
$$$$
\text { if } a+g \leq x \leq L_{t}
$$

Where $\mu$ is the friction coefficient, And $\mathrm{Lt}=\mathrm{a}+\mathrm{g}$ + L. The tension change occurs on the sliding zone. The web velocity is equal to the roll velocity on the sticking zone.

\section{Mass conservation law}

Consider an element of web of length $L=L_{0}(1+\varepsilon)$

With a weight density $\rho$, under an unidirectional stress. The cross section is supposed to be constant. According to the mass conservation law, the mass of the web remains constant between the state without stress and the state with stress

$$
\rho S L=\rho_{0} S L_{0} \Rightarrow \frac{\rho}{\rho_{0}}=\frac{1}{1+\varepsilon}
$$

\section{Tension model between two consecutive rolls.}

The equation of continuity, cf. [8], applied to the web gives:

$$
\frac{\partial \rho}{\partial t}+\frac{\partial(\rho V)}{\partial x}=0
$$

By integrating on the variable $\mathrm{x}$ from 0 to $\mathrm{Lt}$ (cf. Fig. 1), taking into account (4), and using the fact that $\mathrm{a}+\mathrm{g} \ll \mathrm{L}$, we obtain

$$
\frac{d}{d t}\left(\frac{L}{1+\varepsilon_{2}}\right)=\frac{V_{1}}{1+\varepsilon_{1}}-\frac{V_{2}}{1+\varepsilon_{2}} .
$$

Therefore:

$$
-L \frac{d \varepsilon_{2}}{d t}=V_{1} \frac{\left(1+\varepsilon_{2}\right)^{2}}{1+\varepsilon_{1}}-V_{2}\left(1+\varepsilon_{2}\right) \text {. }
$$

This equation can be simplified by using the approximation

$$
\begin{aligned}
& \varepsilon_{1}<<1 \text { and } \varepsilon_{2}<<1 \\
& \frac{\left(1+\varepsilon_{2}\right)^{2}}{1+\varepsilon_{1}} \approx\left(1-\varepsilon_{1}\right)\left(1+2 \varepsilon_{2}\right)
\end{aligned}
$$

And using Hook's law, we get:

$$
\begin{aligned}
& L_{k-1} \frac{d T_{k}}{d t} \cong E S\left(V_{k}-V_{k-1}\right)+T_{k-1} V_{k-1} \\
& -T_{k}\left(2 V_{k-1}-V_{k}\right) . \\
& \mathrm{k}=2,3,4,5 .
\end{aligned}
$$

where $\mathrm{Lk}-1$ is the web length between roll k-1 and roll k, 
$\mathrm{Tk}$ is the tension on the web between roll $\mathrm{k}-1$ and roll $\mathrm{k}, \mathrm{Vk}$ is the linear velocity of the web on roll $\mathrm{k}, \Omega \mathrm{k}$ is the rotational speed of roll $\mathrm{k}, \mathrm{Rk}$ is the radius of roll $\mathrm{k}, \mathrm{E}$ is the Young modulus and $\mathrm{S}$ is the web section.

\section{E. Roll velocity calculation}

The law of motion can be obtained with a torque balance:

$\frac{d\left(J_{k} \Omega_{k}\right)}{d t}=R_{k}\left(T_{k+1}-T_{k}\right)+C e m_{k}+C_{f}$

Where $\Omega_{k}=V_{k} / R_{k}$, is the rotational speed of roll $\mathrm{k}$

$\mathrm{Cem}_{k}$ is the motor torque (if the roll is driven) and $\mathrm{Cf}$ is the friction torque.

\section{F. Complete model of the five motors system}

Fig. 2 shows a typical five motors system with winder, unwinder, and three tractors.

The complete model of this system is given by the following equations:

$$
\begin{gathered}
L_{2} \frac{d T_{3}}{d t}=E S\left(V_{3}-V_{2}\right)+T_{2} V_{2}-T_{3} V_{3} . \\
L_{3} \frac{d T_{4}}{d t}=E S\left(V_{4}-V_{3}\right)+T_{3} V_{3}-T_{4} V_{4} . \\
L_{4} \frac{d T_{5}}{d t}=E S\left(V_{5}-V_{4}\right)+T_{4} V_{4}-T_{5} V_{5} . \\
\frac{d\left(J_{1}(t) \Omega_{1}\right)}{d t}=R_{1}(t) T_{2}+C_{e m 1}-f_{1}(t) \Omega_{1} . \\
\frac{d\left(J_{2} \Omega_{2}\right)}{d t}=R_{2}\left(T_{3}-T_{2}\right)+C_{e m 2}-f_{2}(t) \Omega_{2} . \\
\frac{d\left(J_{3} \Omega_{3}\right)}{d t}=R_{3}\left(T_{4}-T_{3}\right)+C_{e m 3}-f_{3}(t) \Omega_{3} . \\
\frac{d\left(J_{4} \Omega_{4}\right)}{d t}=R_{4}\left(T_{5}-T_{4}\right)+C_{e m 4}-f_{4}(t) \Omega_{4} .
\end{gathered}
$$

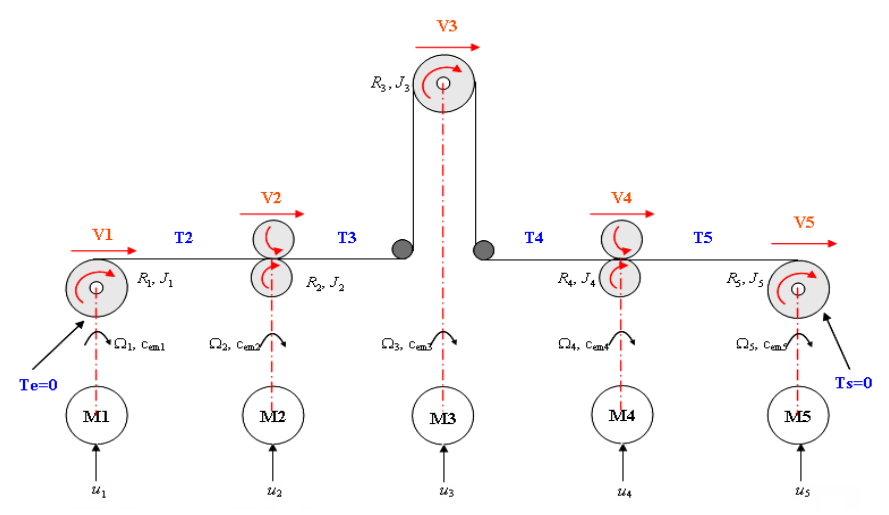

Fig. 2. Simple Web Winding System

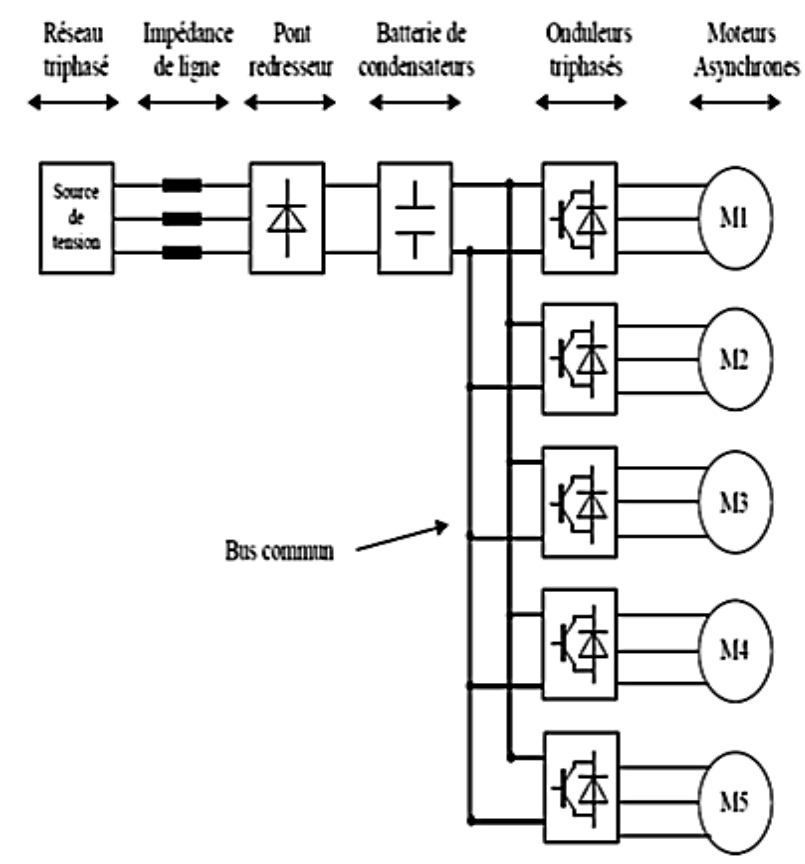

Fig. 3. Electrical part of the five drive system

\section{Controller Design}

\section{A. Linear speed Controller Design}

The speed controller permits to determine the reference torque, the mechanical equation defined as

$$
\frac{\omega_{r}}{C_{e m}}=\frac{P}{f_{c}+J \cdot s}
$$


The diagram of speed controller as shown below

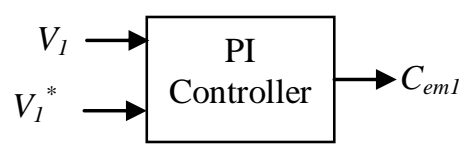

Fig. 4. Linear Speed Controller

The parameters of the PI controller is

$$
\begin{aligned}
K_{i \omega} & =\frac{2 \cdot J \cdot \rho_{\omega}^{2}}{P} \\
K_{p \omega} & =\frac{2 \cdot \rho_{\omega} \cdot J-f_{c}}{P}
\end{aligned}
$$

\section{B. Tension Controller Design}

The proposed tension controller in the system permits to get a linear speed of reference in relation with the strength tension. Thus, we can use (8) as follows:

$$
\frac{d T_{i}}{d t}=\frac{1}{L}\left[-V_{i-1}\left(E S+T_{i-1}\right)+V_{i}\left(E S-T_{i}\right)\right]
$$

While achieving the linearization

$$
V_{a}=-V_{1}\left(E S+T_{1}\right)
$$

The eq (10) become

$$
\frac{d T_{i}}{d t}=\frac{1}{L}\left[V_{a}+V_{i}\left(E S-T_{i}\right)\right]
$$

While introducing the anticipatory term $V_{a}=U+V_{b}$ where $V_{b}=-V_{i}\left(E S-T_{i}\right)$ then we gets

$\frac{d T_{i}}{d t}=\frac{1}{L} U$

This equation allows us to define the structure of controller shows in the Fig 3. Note that this structure contains a controller, an anticipation term as well as a linearization.

This equation allows us to define the structure of controller shows in the Fig 5. Note that this structure contains a controller, an anticipation term as well as a linearization.

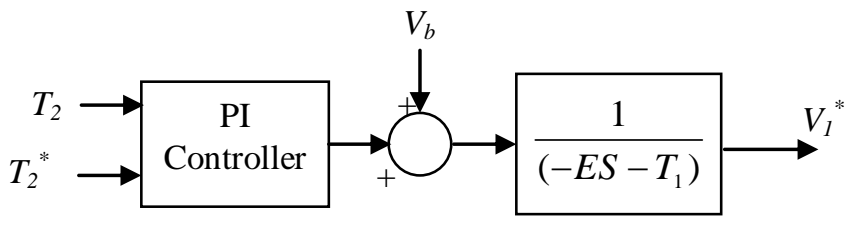

Where the parameters of the PI controller are

$$
\begin{aligned}
& K_{P}=2 \rho L \\
& K_{I}=2 \rho^{2} L
\end{aligned}
$$

In the sequel, the decentralized structure shown on (Fig.4) will be considered. The control structure is composed of 5 elementary controllers associated respectively to each motor.

The cascade control configuration uses the tension as primary measurement and velocity as secondary measurement. The manipulated variable is the torque applied to the motors.

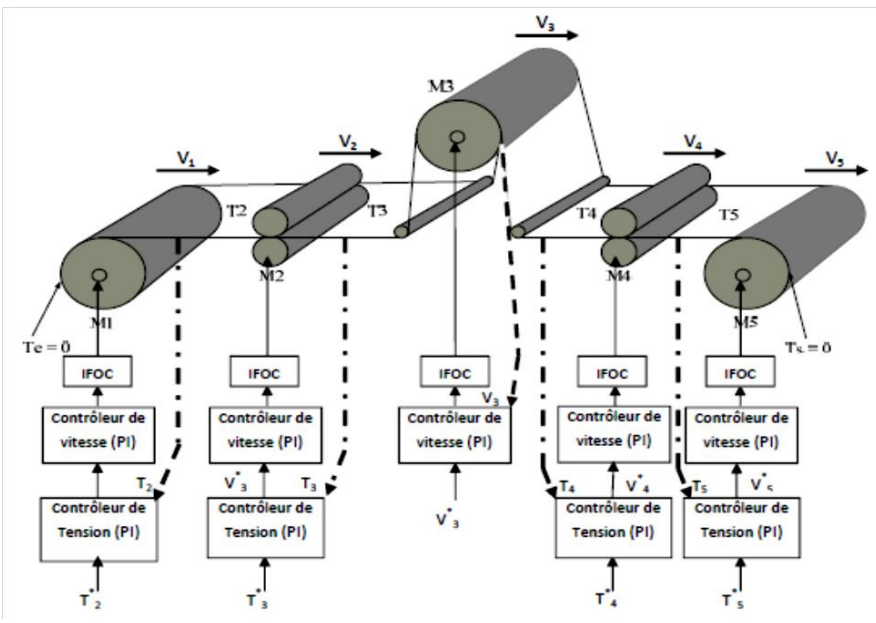

Figure.4. Control structure of a winding system (PI)

\section{Simulation Results}

The winding system we modeled is simulated using MATLAB SIMULINK software and the simulation is carried out on 10s. To evaluate system performance we carried out numerical simulations under the following conditions:

Start with the linear velocity of the web of $5 \mathrm{~m} / \mathrm{s}$.

The motor $\mathrm{M} 1$ has the role of Unwinder a roll radius $\mathrm{R} 1$ $(\mathrm{R} 1=2.25 \mathrm{~m})$.

The motors M2, M3, M4 are the role is to pinch the tape.

The motor M5 has the role of winding a roll of radius R5. The aims of the STOP block is to stop at the same time the different motors of the system when a radius adjust to a desired value (for example R5 $=0.8 \mathrm{~m}$ ), by injecting a reference speed zero.

As shown in Fig (5, a b c d e), an improvement of linear speed, moment of inertia, belt tension, torque, and radius of the coil, and has follows the reference speed for PI controller after $1 \mathrm{sec}$, in all motors.

Fig. 1. Tension Controller 

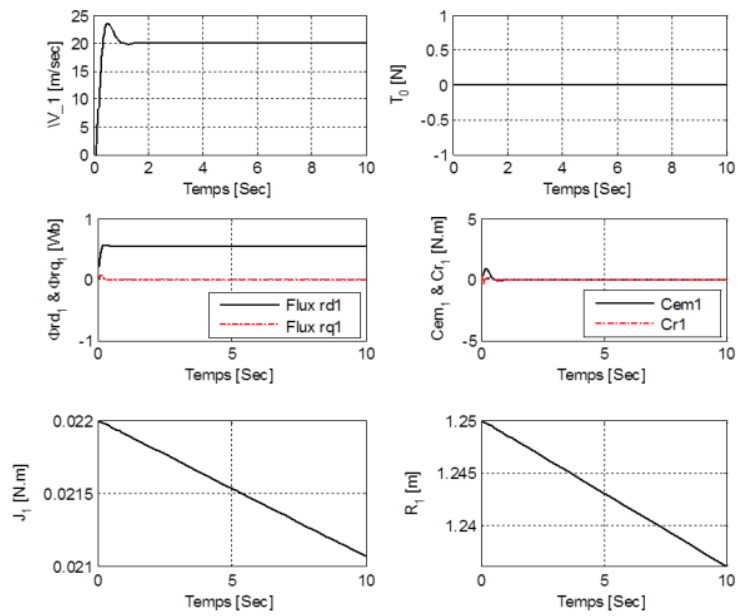

Fig. 5. a): Simulation results of the first motor
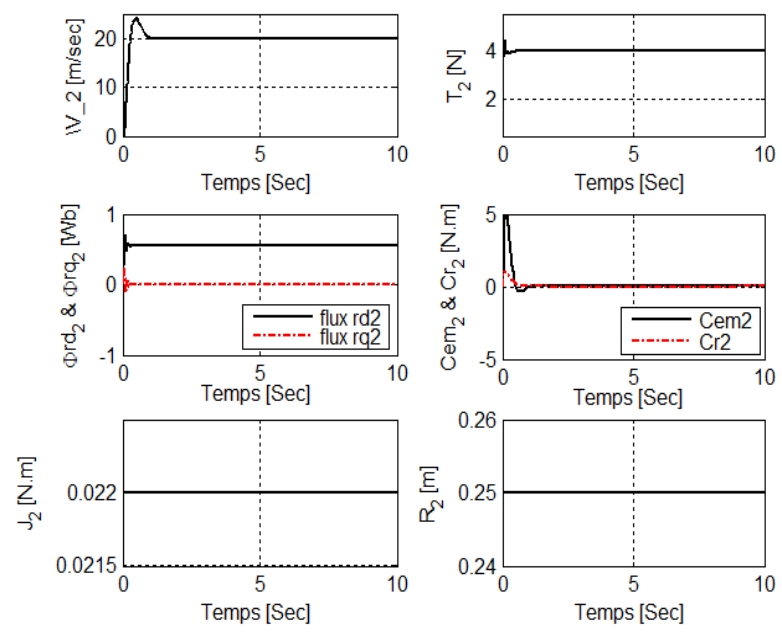

Fig. 5. b): Simulation Results Of The Second Motor
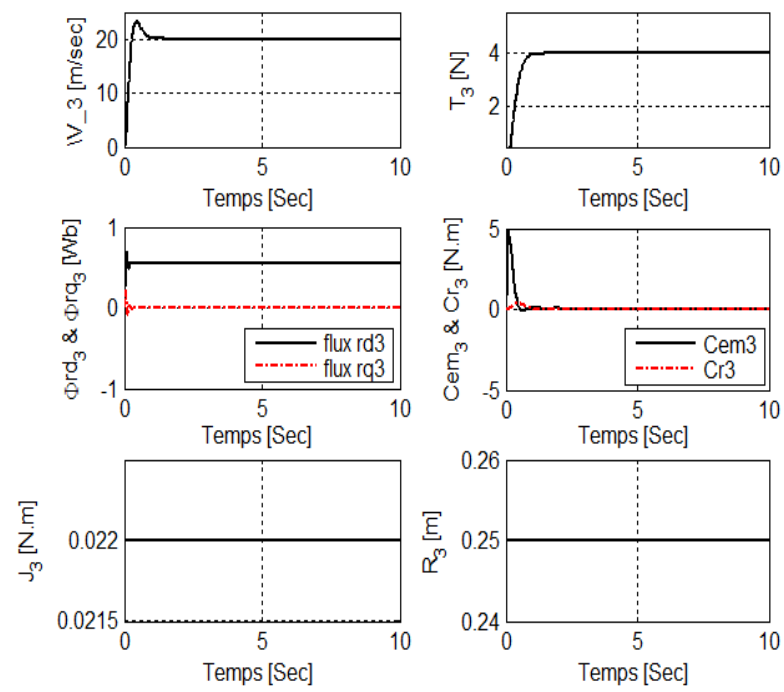

Fig. 5. c): Simulation Results Of The Third motor
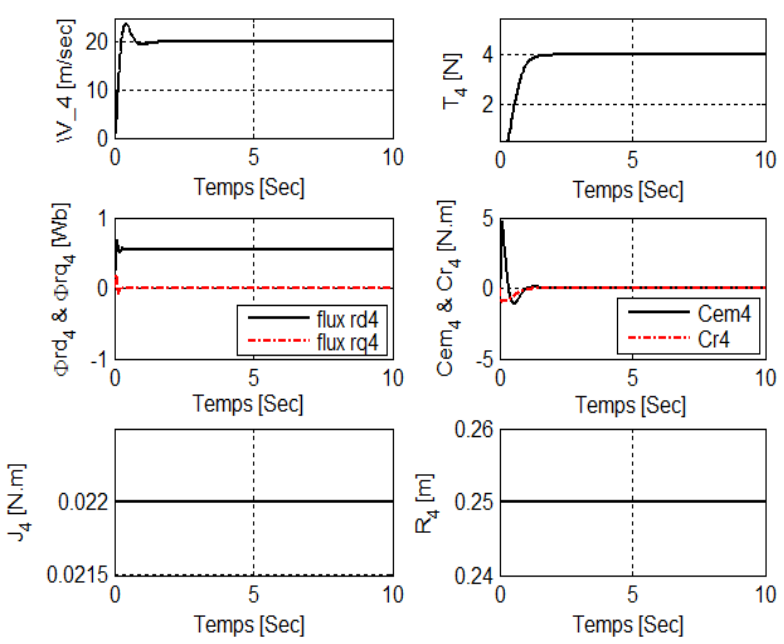

Fig. 5. d): Simulation Results Of The Fourth Motor
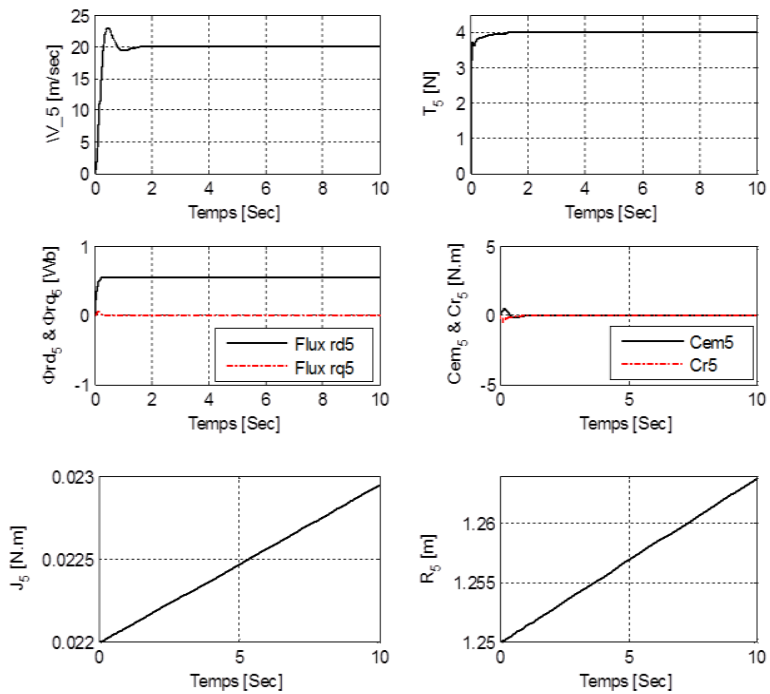

Fig. 5. e): Simulation Results Of The Fifth Motor
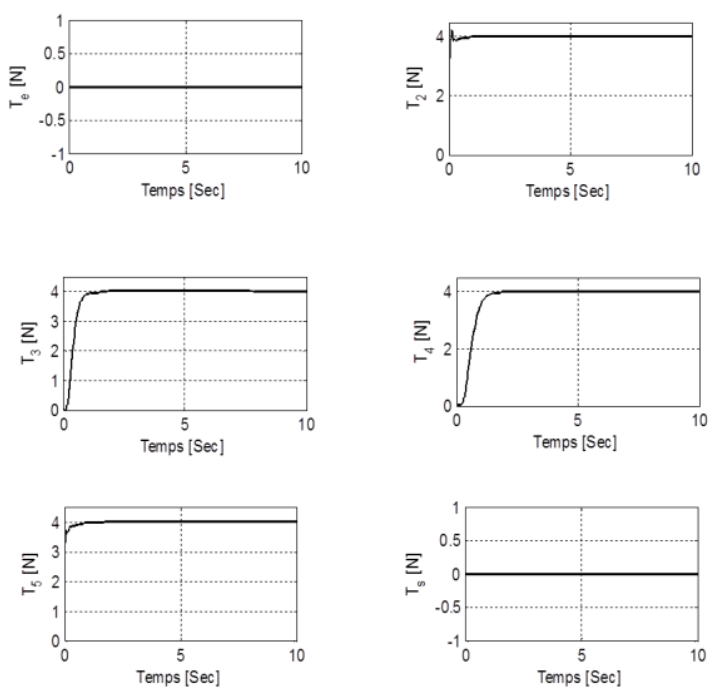

Fig. 6. The Tension Of The Strip 
From the figures (6), we can say that: the tension follows the reference tension with application of PI controller.

It appears clearly that the classical control with PI controller in linear speed control and tension control offers better performances in both of the overshoot control and the tracking error. However is easy to apply.

\section{CONCLUSION}

The objective of this paper consists in developing a model of a winding system constituted of five motors that is coupled mechanically by a strap whose tension is adjustable and to develop the methods of analysis and synthesis of the commands robust and their application to synchronize the five sequences and to maintain a constant mechanical tension between the rollers of the system.

Computer simulations show the robustness and the performance of the winding system with the PI controllers, however PI control dominates industry and it is simple and easy to implement.

\section{REFERENCES}

[1] D. P. Cambell, Process Dynamics, Wiley, 1958, pp.113-156

[2] G. Brandenburg, "New Mathematical Model For Web Tension and Register Error,» Proceedings of the 3rd IFAC Conference on Instrumentation and Automation in The Paper, Rubber and Plastics, Vol. 1, May 1976, pp 411-438.

[3] H. Koç, D. Knittel, M de Mathelin and G. Abba , "Modeling and Robust Control of Winding Systems for Elastic Webs," IEEE Trans. Contr. Syst. Technol., Vol. 10, March 2002, pp.197-208.

[4] J.E. Geddes and M. Postlethwaite, "Improvements in Product Quality in Tandem Cold Rolling Using Robust Multivariable Control," IEEE Trans. Contr. System. Technology. Vol. 6, March 1998, pp. 257-267.

[5] S.H. Jeon, and al., "Decoupling Control of Bridle Rolls for Steel Mill Drive System» IEEE Trans. Ind. Application., Vol. 35, January/February 1999, pp. 119-125.
[6] D. Knittel, and al., "Tension Control for Winding Systems With TwoDegrees of Freedom Hळ Controllers," IEEE Trans. Ind. Applicat. Syst., Vol. 39, January/February 2003, pp. 113-120.

[7] B.T. Boulter, Y. Hou, Z. Gao and F. Jiang., "Active Disturbance Rejection Control for Web Tension Regulation and Control," IEEE Conference on Decision and Control, Orlando, USA, December 2001, pp. 4974- 4979.

[8] F. Mokhtari, P. Sicard, and N. Léchevin, "Damping Injection Control of Winding System Based on controlled Hamiltonian Systems," 12th IFAC Symposium on Automation in Mining, Mineral and Metal Processing (IFAC MMM'07). Québec, Canada, August 2007, pp. 243-248.

[9] F. Mokhtari, P. Sicard, and N. Léchevin, "Stabilizing Winding Systems by Injection Damping Control Based on controlled Hamiltonian Systems," Proc. of IEEE International Electric Machines and Drives Conference (IEMDC'07), Antalya, Turquie, May 2007, pp. 95-100.

[10] Bousmaha Bouchiba, Abdeldejbar Hazzab, Hachemi Glaoui, FELLAH Med-Karim, Ismaïl Khalil Bousserhane "Sliding Mode Speed Control for Multi-Motors System” JAMRIS journal Vol. 4 N 32010 page 50-54.

[11] Christian Thiffault Pierre Sicard Alain Bouscayrol, "Tension Control Loop Using A LinearActuator Based On The Energetic Macroscopic Representation”, CCECE 2004- CCGEI 2004, Niagara Falls, May 2004

[12] S. Charlemagne, A. Bouscayrol, Slama Belkhodja, J.P. Hautier, "Flatness based control of non-linear textile multimachine process", in Proc. of EPE'03, CD-ROM, Toulouse (France), September 2003.

[13] Adlane Benlatreche Dominique Knittel "State Feedback Control with Full or Partial Integral Action for Large Scale Winding Systems" Industry Applications Conference, 2005. Vol. 2 page(s): 973-978 Oct 2005

TABLE I. SYSTEM PARAMETERS

\begin{tabular}{ll|ll}
\hline $\mathrm{E}$ & $1.6 \mathrm{e} 8$ & $\mathrm{~L}_{1}=\mathrm{L}_{2}=\mathrm{L}_{3}[\mathrm{~m}]$ & 5 \\
$\mathrm{~S}\left[\mathrm{~m}^{2}\right]$ & $2.75 \mathrm{e}-3$ & $f_{\mathrm{n}}[\mathrm{Hz}]$ & 50 \\
$\mathrm{R}_{1}[\mathrm{~m}]$ & 1.25 & $\mathrm{~T}_{1 \mathrm{ref}}=\mathrm{T}_{2 \mathrm{ref}}[\mathrm{N}]$ & 4 \\
$\mathrm{R}_{2}=\mathrm{R}_{3}[\mathrm{~m}]$ & 0.25 & $\mathrm{~V}_{2 \text { ref }}[\mathrm{m} / \mathrm{s}]$ & 20 \\
$\mathrm{~J}_{01}=\mathrm{J}_{02}=$ & 0.022 & $p$ & 2 \\
$\mathrm{~J}_{03}\left[\mathrm{Kg} \cdot \mathrm{m}^{2}\right]$ & & & 2 \\
\hline
\end{tabular}

